\section{A Study on the Impact of the PRC's Economic and Marriage Policies after the 1980s on the Marriage Culture of the Chinese Muslims in China}

\author{
Normeanne Joyce A. Sison \\ Georgetown University, Qatar
}

\begin{abstract}
During the 1980s, the government of the People's Republic of China (PRC) introduced marriage reform laws as a way to produce a homogenous society to integrate 56 different ethnic groups, including the Hui minzu or the Chinese Muslims. The PRC also implemented economic reforms that pushed for modernization. The reform of both marriage laws and the economy has had profound social ramifications, especially on the Hui minzu's perceptions of marriage. This paper at its core, explores whether the Huis' compliance to the State policies of marriage denote an inherent shift in their identity as Muslims. To address this issue, representative factors such as wedding couture decisions, composition of wedding portraits, kinship practices, and matrimonial ritual are assessed through personal interviews with Huis and visits to wedding photography studios and wedding couture rental stores in six different cities in China. The fieldwork and study reveal that Huis who reside in cities where the majority of the population is of another ethnic group have become less 'Islamic' in the aspect of marriage and weddings.
\end{abstract}

Keywords: Chinese muslims, marriage, modernization, Islam

\section{Background}

The two waves of Chinese State reconstruction on marriage as well as the economic reforms indirectly impacted the Hui marriage culture. During the first wave of marriage reforms, one of the PRC's strategies to strengthen China as a nation was to shape marriage as a social institution in line with its embrace of modernity. ${ }^{1}$ The rearrangement of the feudal elements of marriage was made to suit the State's socialist ideals. ${ }^{2}$ This meant that polygamy, arranged

\footnotetext{
${ }^{1}$ John Engel, "Marriage in the People's Republic of China: Analysis of a New Law," Journal of Marriage and Family 46, No. 4 (1984): 958.

${ }^{2}$ Matthew Eerie, China and Islam: The Prophet, the Party, and Law (New York: NY Cambridge University Press, 2016), 226.
} 


\section{HPSCONF

\section{October 19-21, 2018 Munich, Germany}

marriage, concubinage, the marriage of minors, and the practice of dowry were all prohibited. ${ }^{3}$ Since most of these practices are observed in Islam, huis are expected to be constrained by these state laws. This paper will problematize the changing hui culture of marriage in China; that as the years progress and the state inclines towards modernization, the farther are the huis' drawn away from legally practicing marriage customs central to their culture. This argument bears important affirmations, including the assertion that the modernizing and coalescing of the Chinese is done at the cost of repressing the ethnic groups' identities; which in this case is presented as the curbing of the hui identity when it comes to the culture of marriage.

\section{Methods}

This research will heavily rely on the conducted fieldwork by the author on her visit to six cities in China, namely: Beijing, Yinchuan, Lanzhou, Linxia, Xunhua, and Xining. Most insights into the current culture of Hui marriage will partially come from interviews with college students, university professors, and a number of mosque leaders called ahongs.

Supplementary information was collected on the author's visit to wedding photography studios and wedding couture stores.

The adequacy of collecting this specific data lies on the accessibility to these businesses that are widespread in the places of conducting the research. The author believes that an explicit comparison could be made in the juxtaposition of wedding pictures from the previous decades and wedding pictures taken in the modern day.

The interviews will encompass the micro level of analysis by assessing individuals' perception of marriage whereas the visit to the wedding photography studios and wedding couture rental stores will represent the macro level of analysis on the society. The methodology of this research demonstrates that the design of approach is suitable for the problem of interest. From the gathered data, the author will evaluate the evidence in light of the previous literature on the research.

The limitations of this research rest on the fact that the author was only given eleven days to visit the mentioned six places in China. The interviews are not as intensive as any anthropological work presented; however, the expected outcome of the interviews will still be regarded as a noteworthy source that contributes to the discipline of modernity and ethnicity.

The author also anticipates the threat to the credibility of the photographic evidence presented in this project since illustrations as such capture only a part of reality. There might

\footnotetext{
${ }^{3}$ John Engel, "Marriage in the People's Republic of China: Analysis of a New Law," Journal of Marriage and Family 46, No. 4 (1984): 958.
} 


\section{HPSCONF

\section{October 19-21, 2018 Munich, Germany}

be some bias in the photographs given that there is already bias in her decision in the framing of the photos. Nonetheless, the photographs are still key evidence in this research and will be used as necessary supplementary tools in proving her hypothesis.

\section{Results}

The empirical testing of this research will be divided into four sections, namely: 1) Mate selection 2) Islamic marriage practice of Endogamy 3) Matrimonial ritual and 4) Wedding aesthetics. Each section will briefly discuss the pre-1980s Hui practices and compare it to the present Hui practices. Section one will trace the historic practice and the importance of spouse selection in the marriage culture. It will try to capture the changing views on spouse selection by including interviews with both young and old Huis. Section two will cover the significance of practicing endogamy among the Hui and discuss the challenge of upholding this practice. Section three will examine Hui wedding rituals and Hui marriage formalities before the state. The last section will consist of Hui couture decisions and Hui wedding portrait composition.

\section{Mate Selection}

In China, matchmakers (meiren) played a significant role in determining one's spouse. ${ }^{4}$ The notion of "face" is important in Hui culture. Marriages based on the children's preferences were not honored by the traditional Hui family. ${ }^{5}$ Huis believed that a marriage made through a matchmaker is a virtuous act similar to constructing a mosque, thus, marriages based on independent choice were discouraged. ${ }^{6}$ Arranged marriages were common in the Hui culture throughout the $18^{\text {th }}$ century. A combination of factors is considered in these types of marriages such as maintaining or attaining wealth, forming a political medium of alliance, or following religious denominations. Parental arrangement in the $18^{\text {th }}$ century exhibited how the decisions of the parents dominated the process of mate selection.

Nowadays, however, there are several ways for a Hui to select a potential spouse. The rise of technology and the widespread use of dating websites have increased social mobility which in effect, fostered individualism. Attending blind dates initiated by friends is also a common

\footnotetext{
${ }^{4}$ Goncalo Santos and Stevan Harrell, Transforming Patriarchy: Chinese Families in the Twenty-First Century (Seattle: University of Washington Press, 2017), 76.

5 Atsuko Shimbo, "The Lifestyle Transformation of Hui Muslim Women in China: A Comparison of Modern and Islamic Education,” Journal of Contemporary East Asia Studies 6, No. 1 (2017): 45.

${ }^{6}$ Atsuko Shimbo, "The Lifestyle Transformation of Hui Muslim Women in China: A Comparison of Modern and Islamic Education,” Journal of Contemporary East Asia Studies 6, No. 1 (2017): 45.
} 


\section{HPSCONF

\section{October 19-21, 2018 Munich, Germany}

practice these days in addition to using dating websites. ${ }^{7}$ Individualism manifested not only in the mechanisms of spousal selection but also in the Chinese's criteria in choosing their life partner. A 1989 report on the mate selection criteria in China presented that males only focused on the female's housekeeping capabilities and that females only looked at whether the male could provide marital sustenance. ${ }^{89}$ Both sexes' demands for each other has dramatically shifted, reflecting the underlying changes in China's social, economic, cultural, and political background. The author is interested in finding out whether the Huis' mate selection methods and criteria follow the contemporary Chinese trend or whether they deviate from these practices.

In the author's visit to Yinchuan, she was able to talk to Ma Hao, a Hui male graduate student. She asked him what his ideal wife is and according to him, it is not necessary that the woman be Hui although it would be better if she is. ${ }^{10} \mathrm{He}$ looks out for a family-oriented woman who would simply reciprocate his affection. ${ }^{11} \mathrm{Ma}$ Hao mentioned that his parents are openminded individuals when it comes to marriage and would accept his decisions. ${ }^{11}$ On the other hand, May, Hui female graduate student and colleague of Ma Hao, stressed that her parents are also lenient towards her choice of spouse. ${ }^{12}$ She thinks this is because she has been a source of income in her family and has helped in the family expenses especially in sending her siblings to school. ${ }^{13}$ She does not have any plans for getting married anytime soon. ${ }^{14}$ Perhaps the growing employment opportunities for Hui women in a highly urbanized city like Yinchuan

\footnotetext{
${ }^{7}$ Wang Feng and Yang Quanhe, "Age at Marriage and the First Birth Interval: The Emerging Change in Sexual Behavior Among Young Couples in China," Population and Development Review 22, no. 2 (1996): 301.

${ }^{8}$ Yinhe Le, “The Mate Selection Criteria in Contemporary Chinese.” Social Sciences in China No. 4 (1989):

9.

${ }^{10}$ Ma Hao, interviewed by author at Northern Minzu University, 11 May 2018.

${ }^{11}$ Ibid. ${ }^{11}$

Ibid.

${ }^{12}$ May, interviewed by author at Northern Minzu University, 11 May 2018.

${ }^{13}$ Ma Hao, interviewed by author at Northern Minzu University, 11 May 2018.

${ }^{14}$ Ibid.
} 


\section{HPSCONF

\section{October 19-21, 2018 Munich, Germany}

have solidified their sense of agency and made marriage less necessary as a means to obtain sustenance.

It is interesting to note that in a place like Xining where the majority is Hui, an ahong or a mosque leader's response to these changes in the mate selection of the Hui youth is that these are just visual changes. ${ }^{15}$ In Xining, amidst these visual changes, the traditional Hui practice of the parents' involvement in spousal selection is still observed. ${ }^{16}$ In this section, the limited anecdotal evidence supports the hypothesis that as Huis move farther from a Hui-majority city to a Han-majority city, the more freedom there is in selecting their prospective spouse.

\section{Endogamy in Islam}

The Islamic order of Hui marriage promotes endogamy because it is a means of maintaining their identity whilst socially controlling society. It is important to keep their community pure by propagating Islam within its ethnic boundaries. ${ }^{17}$ In Northwest or Southwest China where Huis are considerably populous, finding an appropriate Hui spouse is not as difficult as finding one in isolated Hui communities in Han majority areas. ${ }^{18}$ Hence, some Hui households in these isolated communities have resulted to practicing consanguineous endogamy which became problematic in the field of clinical genetics because of the genetic disorders it causes on the offspring. I am interested to know if the onset of the

PRC's promotion of inter-ethnic marriage has shifted the practice of endogamy in these types of Hui communities.

Tie Guoxi, an ahong at the Niujie mosque in Beijing, stressed that as an officiator of Hui weddings, he only encountered a few Hui to non-Hui weddings. ${ }^{19}$ This is an interesting point because I was expecting that the number of inter-ethnic marriages would be significantly large in an urbanized city like Beijing. Ahong Guoxi's observation suggests that the number of Huis residing in Beijing is increasing, making it easier for the Huis to find a partner for marriage.

Ding Shiren, a professor from Lanzhou University School of History and Humanities, affirmed that endogamy is still a widespread practice among the Huis and that the PRC's

\footnotetext{
${ }^{15}$ Xining ahong, in discussion with author at Dongguan mosque, 16 May 2018.

16 Ibid.

${ }^{17}$ Dru Gladney, Muslim Chinese: Ethnic Nationalism in the People's Republic (Massachusetts: Harvard University Press, 1991), 249.

${ }^{18}$ Ibid, 243.

${ }^{19}$ Tie Guoxi. in discussion with author at Niujie mosque, 8 May 2018.
} 


\section{HPSCONF

\section{October 19-21, 2018 Munich, Germany}

promotion of inter-ethnic marriages has little to no effect. ${ }^{20}$ This was because of the incompatibility in the lifestyle between the Huis and Hans. ${ }^{21}$ The professor mentioned that even though the state encourages the union of two different minzus, the sense of agency developed by each individual has enabled him or her to decide on who to marry. ${ }^{22} \mathrm{He}$ asserted that, as part of human nature, it is but natural for someone to choose a person who understands their culture and shares the same belief. ${ }^{23}$ Therefore, endogamy remains to be a vital marital custom to the Huis' culture of marriage today. ${ }^{24}$

\section{Matrimonial Ritual}

Hui weddings are more elaborate and more intimate in comparison to Han weddings. ${ }^{25}$ Since Huis work in a private enterprise in carrying out the ceremony, they are able to come up with more expensive weddings. ${ }^{26}$ A Han wedding typically lasts for a day with the ceremony held first which is then followed by the reception. ${ }^{27}$ A Hui wedding spanned for at least four days beginning with grand banquets in the respective houses of the bride and groom. The second day is the actual wedding day where the couple exchanges their vows in front of the ahong and sign their marriage 'contract.' On the third day, the bride spends the day in her new husband's house but is sent to sleep at her natal home. The last day is where the bride is escorted by her family to her 'new house,' marking the beginning of her conjugal journey with her spouse. In addition to the difference in the wedding ritual proper, unlike Han wedding receptions, alcoholic beverages and pork in Hui wedding receptions are not served because of the Islamic prohibition of these two things. Despite the differences in the Hui and Han

\footnotetext{
${ }^{20}$ Ding Xiren, interviewed by author at Lanzhou University, 12 May 2018.

21 Ibid.

${ }^{22}$ Ibid.

23 Ibid.

24 Ibid.

${ }^{25}$ Maris Boyd Gillette, Between Mecca: Modernization and Consumption among Urban Chinese Muslims (Stanford, California: Stanford University Press, 2000), 196.

${ }^{26}$ Maris Boyd Gillette, Between Mecca: Modernization and Consumption among Urban Chinese Muslims (Stanford, California: Stanford University Press, 2000), 196.

${ }^{27}$ Ibid.
} 


\section{HPSCONF

\section{October 19-21, 2018 Munich, Germany}

matrimonial ritual, there are still some structural elements that are common in both cultures related to the formation of a relationship between the bride's and the groom's families. ${ }^{28}$

Xining's Dongguan mosque had a mini-museum that contained the surrounding community's religious and cultural information. The museum included a section on marriage and the matrimonial ritual. This shows that nothing has significantly changed in the ceremony of Hui weddings. However, Mohammed Al-Sudairi, a research fellow at the King Faisal Center for Research and Islamic Studies mentioned that the Huis' religious ritual for marriage is not recognized by the state. ${ }^{29}$ This implies that Hui couples must first register their marriage to the local government in order to be acknowledged as husband and wife by the government. Concluding this section, the structure of Hui matrimonial rituals may not have changed over the years, however, the PRC's requirement of a civil marriage has somehow delegitimized Islamic marital ritual by not recognizing the unity of Hui couples bonded by the religion.

\section{Couture Decisions}

The historical reconstruction of Hui wedding attires was heavily influenced by two main factors: the interpretation of the clothing's color and the association of style to social classes. During the 1920s, Hui women preferred to wear red qipaos, a long and tight skirt worn in imperial China. ${ }^{30}$ Red because it is considered the traditional color of bridal clothes in China. ${ }^{31}$ Their preference on wearing the qipao came from its imperial connotation of wealth and elegance. Perhaps another reason why female Huis wore it to their wedding was that its style was mostly conservative, not revealing a lot of skin. Then came the 1990s where white wedding gowns became a worldwide trend. The traditional notion of social classes and color schemes when it came to couture decisions were abandoned in pursuit of the generic sophisticated look. As time progressed, acquiring a splendid wedding gown became less costly because of the number of stores that supplied different styles of wedding gowns.

Throughout the trip, the author visited two to four wedding clothes stores in each city she went to. Her findings show that there are two types of shops where people purchase their wedding clothes from; either an actual wedding planner studio where the clothes are already

\footnotetext{
${ }^{28}$ Ibid.

${ }^{29}$ Mohammed Al-Sudairi interviewed by author at Linxia, 15 May 2018.

${ }^{30}$ Maris Boyd Gillette, Between Mecca: Modernization and Consumption among Urban Chinese Muslims (Stanford, California: Stanford University Press, 2000), 194.

${ }^{31}$ Ibid.
} 


\section{HPSCONF

\section{October 19-21, 2018 Munich, Germany}

inclusive of the wedding package, or from a gown shop where gowns and dresses for different occasions could be found.

In her visit to the gown shops in Beijing and Yinchuan, most weddings gowns were sold in red. When the storekeeper in Beijing was asked about the best-selling dress for the Hui minzu, the storekeeper pointed to a green wedding dress that resembled an Indian wedding dress.

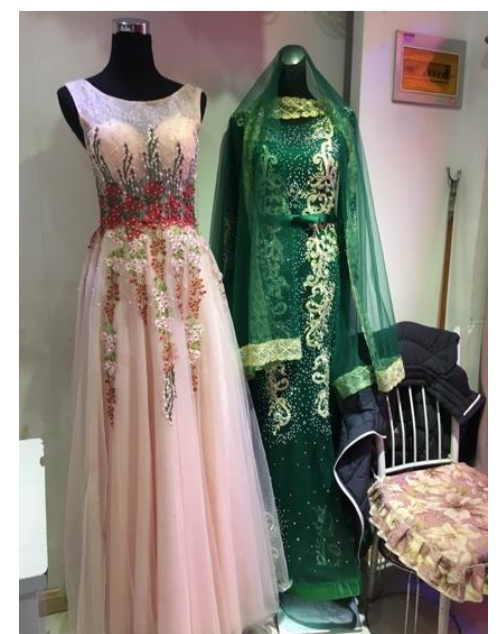

Figure 6: Beijing's best-selling Hui wedding dress in green. Photograph by author, May 8, 2018.

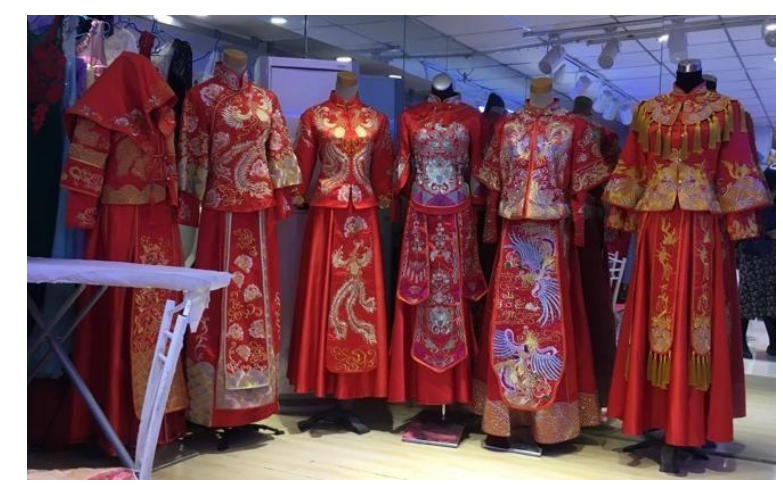

Figure 7: Wedding dresses at a gown shop in Yinchuan. Photograph by author, May 11, 2018.

Lanzhou has a special shopping center dedicated to Hui women. Most shops sold casual clothes, hair accessories, and shoes. There was only one shop that sold formal dresses which included wedding gowns. Just like in Beijing, the popular styles were similar to Indian wedding gowns. However, Hui women still look to Western wedding couture. Since the current trend in Western fashion is the use of lace, the best-selling white gown in Lanzhou also bears intricate lace designs. I would also like to point out that the pictured white wedding gown is not only 


\section{HPSCONF

\section{October 19 - 21, 2018 Munich, Germany}

representative of Western culture, but also of the Arabian wedding culture. Arabian brides often wear conservative yet magnificent white wedding gowns full of volume and of diamonds. ${ }^{32}$

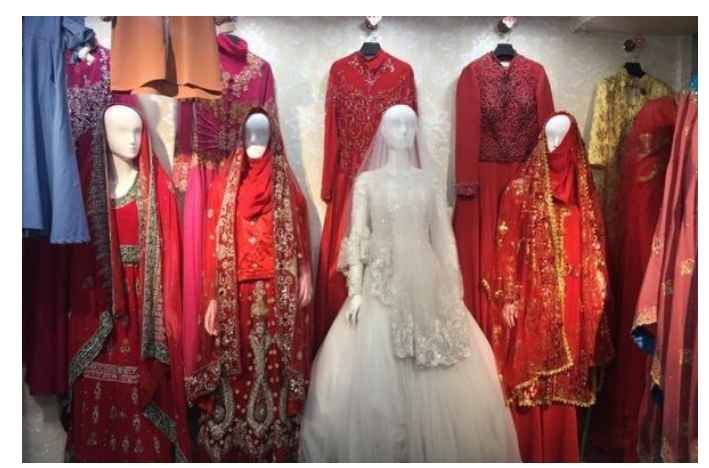

Figure 8: Popular wedding dresses in the Hui women's shopping complex at Lanzhou. Photograph by author, May 13, 2018.

The last shop the author visited was a rental store in Xining. It was striking to see the different colors of dresses. Such variety of colors were not observed in the other cities. Perhaps in cities where the Huis are the majority, the market demand for red wedding gowns is low. This could mean that the use of traditional Chinese wedding dresses is becoming less popular in these areas.
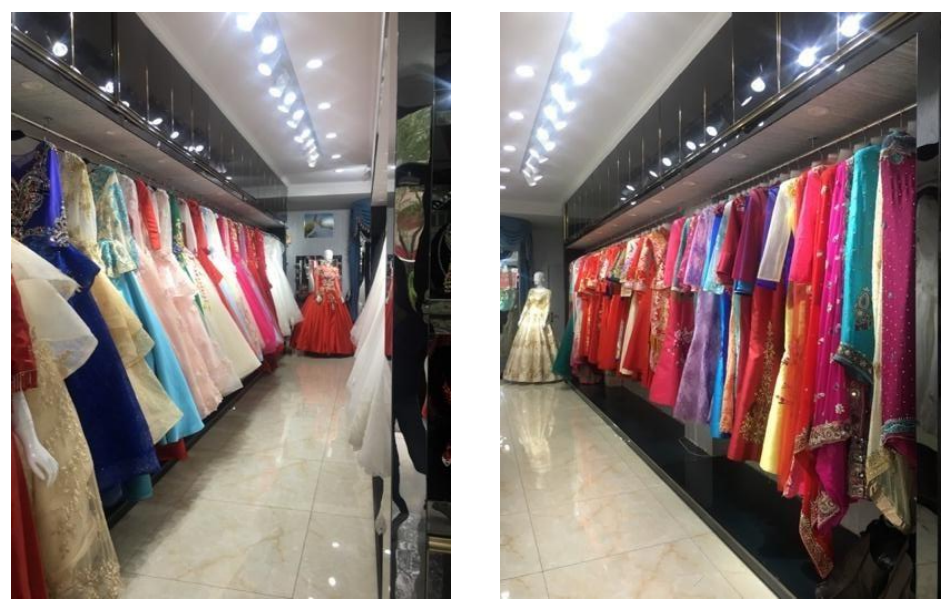

Figures 10-11: Inside a couture rental store in Xining. Photograph by author, May 16, 2018.

Based on the findings, the author argues that nowadays, Hui couture decisions are not influenced any more by the color or the social class representation of the clothes. They are instead influenced by whatever the current trend is today. As long as the dresses are not

\footnotetext{
32 This is based on the author's observation on the Arab weddings she was invited to attend in the last four years.
} 


\section{HPSCONF

\section{October 19-21, 2018 Munich, Germany}

provocative, the color and style are really up to their preference. The growing market for Indian and Arabian inspired wedding dresses signifies that Hui women have gone beyond the Western world in search of their image of an ideal wedding dress. A connection to the Arab world is established by the fact the Hui women look up to Arab wedding fashion. I think this strengthens the identity of a Hui woman because she associates her couture decision to another Muslim woman coming from a different part in the world.

\section{Wedding Portrait Compositions}

The wave of Western influence on the imagery of a modern proper couple is evident in the thriving businesses of wedding photographers in China. ${ }^{33}$ First and foremost, portraits are important in the Chinese culture because it is a medium that could be passed on to generations for ancestral veneration. Hence, portrait composition in weddings is a significant aspect because it reveals how the Hui couple want to be represented as. The author assumes that Huis would also incline to such practices of wedding photo shoots in locations that are significant, incorporating symbols central to their identity.

In the findings, wedding portraits in China have now evolved to be wedding photo shoots that had a theme. Some of the common themes were Bohemian, French, luxurious, dreamy, and street-style. According to a wedding planner in Lanzhou, the motif for wedding photo shoots has evolved dramatically because every couple aimed to stand out. Not only were these pictures framed inside the couple's house, the pictures were also uploaded to their social media accounts for everyone else to see. The agent also expressed his dismay towards couples who opt for a wedding photo shoot in cities out of China. He stressed that the Chinese identity in these photo shoots is slowly fading with the incorporation of foreign themes. Also, traditional photo shoots are seldom chosen by their clients.
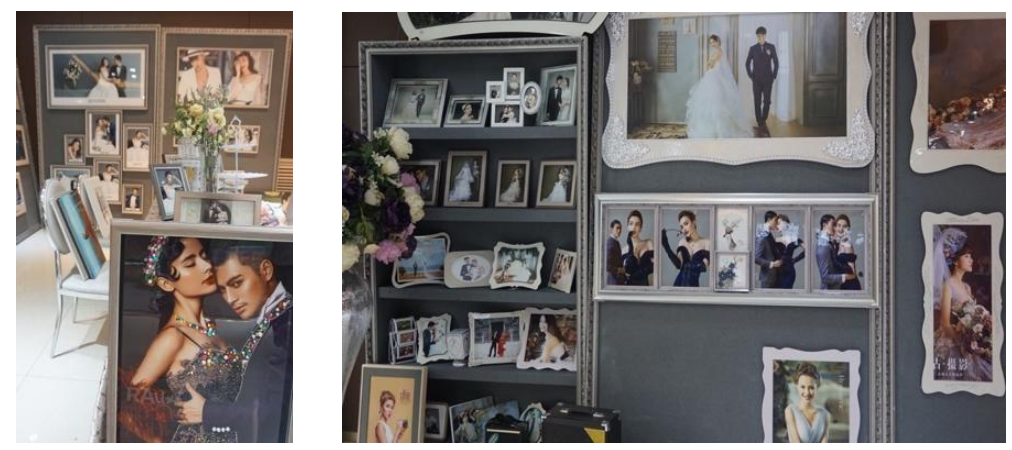

\footnotetext{
${ }^{33}$ Eriberto Lozada, "Framing Globalization: Wedding Pictures, Funeral Photography, and Family Snapshots in Rural China," Visual Anthropology 19, no. 1 (2006): 90.
} 


\section{HPSCONF

\section{October 19 - 21, 2018 Munich, Germany}

Figures 12-13: Inside a wedding planning studio at Lanzhou. Photograph by author, May 13, 2018.

On a collective level, the results of the author's fieldwork in China supports her hypothesis for this research paper. Her assumption that Huis have become less 'Islamic' is complemented by the changing culture of Hui marriage in the aspects of mate selection, wedding couture decision, and wedding portraits. Although endogamy persists as a marital practice, it might cease to exist in the future if the PRC amends its marriage laws in favor of inter-ethnic marriages. Overall, the state is not the only one responsible for the changing marriage culture of the Huis. China indeed is similar to other countries where the social mentality of its people is influenced by a variety of other factors such as the economy, the global competition, and many more. ${ }^{34}$ These in effect, affect the younger generations' perception of marriage, including the Huis'. ${ }^{35}$ The external changes are just as impactful as the PRC's internal change on the marriage setting of China.

\section{References}

Allès, Elisabeth. "The Dungans and the Marriage Ceremony: A Case of Multiple Identities." China Perspectives, no. 27 (2000): 62-69.

Croll, Elisabeth. China's New Consumers: Social Development and Domestic

Demand. London: Routledge, 2006.

Ding Xiren, interviewed by author at Lanzhou University, 12 May 2018.

Erie, Matthew. China and Islam: The Prophet, the Party, and the Law. Cambridge: Cambridge University Press, 2016.

Engel, John W. "Marriage in the People's Republic of China: Analysis of a New Law." Journal of Marriage and Family 46, no. 4 (1984): 955-61. doi:10.2307/352547.

Feng, Wang, and Yang Quanhe. "Age at Marriage and the First Birth Interval: The Emerging Change in Sexual Behavior Among Young Couples in China." Population and Development Review 22, no. 2 (1996): 299-320. doi:10.2307/2137436.

Gillette, Maris Boyd. Between Mecca and Beijing Modernization and Consumption among Urban Chinese Muslims. Stanford: Stanford University Press, 2000.

Gladney, Dru. Muslim Chinese: Ethnic Nationalism in the People's Republic. Harvard University Press, 1991.

\footnotetext{
${ }^{34}$ Ma Rong, in discussion with author at Beijing University, 10 May 2018.

${ }^{35}$ Ibid.
} 


\section{HPSCONF

October 19 - 21, 2018 Munich, Germany

Le, Yinhe. "The Mate Selection Criteria in Contemporary Chinese." Social Sciences in China No. 4 (1989): 61-74.

Lozada, Eriberto, "Framing Globalization: Wedding Pictures, Funeral Photography, and Family Snapshots in Rural China." Visual Anthropology 19, no. 1 (2006): 87103, DOI: $10.1080 / 08949460500374049$

Ma Hao, interviewed by author at Northern Minzu University, 11 May 2018.

Ma Rong, in discussion with author at Beijing University, 10 May 2018.

May, interviewed by author at Northern Minzu University, 11 May 2018.

Mohammed Al-Sudairi, interviewed by author at Linxia, 15 May 2018.

Shimbo, Atsuko. "The Lifestyle Transformation of Hui Muslim Women in China: A Comparison of Modern and Islamic Education," Journal of Contemporary East Asia

Studies 6, No. 1 (2017): 42-61. doi:10.1080/24761028.2017.131275

Sison, Normeanne Joyce. 2018. All photographs in this research. China. Tie

Guoxi. in discussion with author at Niujie mosque, 8 May 2018.

Wang, Yajun. “Spouse Selection Amongst China's Post-1980 Generation.” Master's thesis, Central European University, 2012.

Wedding planner, interviewed by author at Lanzhou with the help of translating skills of Amber and Crystal from Lanzhou University, 13 May 2018.

Xining ahong, in discussion with author at Dongguan mosque, 16 May 2018. 